\title{
A Structural Analysis of Price Discovery Measures*
}

\author{
Bingcheng Yan ${ }^{\dagger}$ and Eric Zivot ${ }^{\ddagger}$
}

April 5, 2007

\begin{abstract}
We analyze the structural determinants of two widely used measures of price discovery between multiple markets that trade closely-related securities. Using a structural cointegration model, we show that both the information share (IS) and component share (CS) measures account for the relative avoidance of noise trading and liquidity shocks, but that only the IS can provide information on the relative informativeness of individual markets. In particular, the IS of one market is higher if it incorporates more new information and/or impounds less liquidity shocks. Use of the CS in conjunction with the IS can help sort out the confounding effects of the two types of shocks. Furthermore, we find that the IS only accounts for the immediate (one-period) responses of market prices to the news innovation which implies that the IS estimates based on high sampling frequencies may be distorted by transitory frictions and may miss important price discovery dynamics.
\end{abstract}

${ }^{*}$ We thank Geoffrey Booth, Thierry Foucault, Frederick Harris, Jennifer Koski, Bruce Lehmann, Thomas McInish, Charles Nelson, Edward Rice, Richard Startz, seminar participants at the European RTN Economics and Econometrics of Market Microstructure Summer School (2004), seminar participants at the European Meeting of the Econometric Society (2004), and an annonymous referee for helpful comments. All remaining errors are our own.

${ }^{\dagger}$ Barclays Global Investors, San Francisco, CA. email: yanbc@yahoo.com.

${ }^{\ddagger}$ Department of Economics, University of Washington, Seattle, WA. email: ezivot@u.washington.edu. 


\section{Introduction}

Price discovery is the dynamic process by which market prices incorporate new information, and is arguably one of the most important functions of financial markets. A notable trend in financial markets is the trading of identical or closely related assets in multiple markets. The important issues related to price discovery are determining which market first incorporates new information about the underlying fundamental asset, and how the efficacy of price discovery depends on trading mechanisms, market liquidity, and the prevalence of asymmetric information.

There are two widely used measures of price discovery for multiple markets that share a common random walk efficient price (fundamental value). Hasbrouck (1995) focuses on the variance of the efficient price innovation, and defines one market's information share (IS) as the proportion of the efficient price innovation variance attributable to that market. In contrast, Booth et. al. (1999), Chu et. al. (1999), and Harris et. al. (2002), adopting the permanent-transitory decomposition technique in Gonzalo and Granger (1995), focus on the composition of the efficient price innovation and measure one market's contribution to price discovery by the component weight of that market in forming the efficient price innovation. Hereafter, we refer to this measure of price discovery as component share (CS). Despite their different

focuses, both approaches use cointegration to constrain multiple market prices to share a common efficient price, and both approaches use a reduced form vector error correction (VEC) model for estimation purposes.

Our analysis is motivated by the recent debate and discussion about the interpretation of CS and IS. As illustrated by the papers in the special issue on price discovery of the Journal of Financial Markets (JFM) (Issue 3, 2002), there has been substantial confusion in the literature over what the IS and CS imply for price discovery measurement. The fundamental cause of this confusion is that both measures are defined in terms of the reduced form forecasting errors of individual markets from 
an empirical VEC model. This view is emphasized by Lehmann (2002) who states "This muddled state is unsurprising because the error correction model is a reduced form and the role of each market in price discovery depends on the parameters of the structural model."

In this paper, we directly address Lehmann's concern regarding the interpretation of the IS and CS by proposing a structural cointegration model for the price changes in multiple markets. Our model features two types of structural price shocks: a permanent news innovation to the common fundamental value, and a transitory liquidity/noise trading shock. We show that the reduced form VEC forecasting errors are a mixture of these structural shocks, and this linkage allows us to analyze the dependency of the CS and IS on how individual markets respond to informational and non-informational shocks.

Our results show that both the information share (IS) and component share (CS) measures account for the relative avoidance of noise trading and liquidity shocks, but that only the IS can provide information on the relative informativeness of individual markets. In particular, the IS of one market is higher if it incorporates more new information and/or impounds less liquidity shocks. Use of the CS in conjunction with the IS can help sort out the confounding effects of the two types of shocks. Furthermore, we find that the IS only accounts for the immediate (one-period) responses of market prices to the news innovation. As a result, the IS estimates based on high sampling frequencies may be distorted by transitory frictions and misrepresent which market moves first in the response to new information.

The rest of the paper is organized as follows. In Section 2, we review the derivation of the CS and IS from a reduced form cointegration model. In Section 3, we propose a structural cointegration model for the price changes in arbitrage linked markets and show that our model is consistent with several stylized market microstructure models from the extant literature. We derive the structural analysis of the IS and CS in Section 4, and we illustrate our main results with analytical examples and simulation 
exercises. Our conclusions and suggestions for future research are presented in Section 5. Some technical derivations are given in the Appendix.

\section{Reduced Form Price Discovery Cointegration Model}

Consider a single asset trading in two distinct markets ${ }^{1}$. Let $\mathbf{p}_{t}=\left(p_{1, t}, p_{2, t}\right)^{\prime}$ denote a $2 \times 1$ vector of $(\log )$ prices for the asset from the two markets. In a multipletrading environment, these prices may be the trade prices or quotes from different trading venues. More generally, the prices may be an asset's cash market price and the price of its derivatives, or the observed price of an asset and its price synthetically constructed from other financial assets. As a result, these prices are closely linked by arbitrage. We assume each of these prices contains a random walk component, so that $\mathbf{p}_{t}$ is a nonstationary process. In time series terminology, these prices are integrated of order 1 , or $I(1)$, and the price changes, $\Delta \mathbf{p}_{t}$, are integrated of order zero, or $I(0)$. We assume that $\Delta \mathbf{p}_{t}$ has a bivariate moving average (MA) or Wold representation ${ }^{2}$

$$
\begin{aligned}
\Delta \mathbf{p}_{t} & =\boldsymbol{\Psi}(L) \mathbf{e}_{t}=\mathbf{e}_{t}+\boldsymbol{\Psi}_{1} \mathbf{e}_{t-1}+\boldsymbol{\Psi}_{2} \mathbf{e}_{t-2}+\cdots \\
\Psi(L) & =\sum_{s=0}^{\infty} \boldsymbol{\Psi}_{k} L^{k}, \quad \Psi_{0}=\mathbf{I}_{2}
\end{aligned}
$$

where $\mathbf{e}_{t}$ is a $2 \times 1$ vector satisfying $E\left[\mathbf{e}_{t}\right]=\mathbf{0}$ and

$$
E\left[\mathbf{e}_{t} \mathbf{e}_{s}^{\prime}\right]=\left\{\begin{array}{cc}
\mathbf{0} & \text { if } t \neq s \\
\boldsymbol{\Sigma} & \text { otherwise }
\end{array}\right.
$$

The matrix polynomial $\boldsymbol{\Psi}(L)=\boldsymbol{\Psi}(1)+(1-L) \boldsymbol{\Psi}^{*}(L)$ has the property that the elements of $\left\{\boldsymbol{\Psi}_{k}\right\}_{k=0}^{\infty}$ are 1-summable and $\boldsymbol{\Psi}(L)$ is full rank everywhere on $|z| \leq 1$.

\footnotetext{
${ }^{1}$ For simplicity, we focus on the two market case. Our analysis can be extended to the $n$ market case. See Yan and Zivot (2006) for details.

${ }^{2}$ We omit any deterministic terms in the Wold representation for ease of exposition.
} 
Since the prices in $\mathbf{p}_{t}$ are for the same underlying asset, they are not expected to drift far apart from each other and so the difference between them should be $I(0)$. Formally, we assume that $\mathbf{p}_{t}$ is cointegrated with known cointegrating vector $\boldsymbol{\beta}=$ $(1,-1)^{\prime}$ so that $\boldsymbol{\beta}^{\prime} \mathbf{p}_{t}=p_{1 t}-p_{2 t}$ is $I(0)$. It follows from the Granger Representation Theorem (Engle and Granger, 1987) that $\boldsymbol{\Psi}(1)$ has rank 1, $\boldsymbol{\beta}^{\prime} \mathbf{\Psi}(1)=\mathbf{0}$, and there exists a $2 \times 1$ vector $\boldsymbol{\alpha} \neq \mathbf{0}$ such that $\mathbf{\Psi}(1) \boldsymbol{\alpha}=\mathbf{0}$. Furthermore, $\mathbf{p}_{t}$ has a vector error correction (VEC) model representation of infinite order which can be approximated by the finite order $\operatorname{VEC}(K-1)$ model:

$$
\Delta \mathbf{p}_{t}=\boldsymbol{\alpha}\left(\boldsymbol{\beta}^{\prime} \mathbf{p}_{t-1}-\mu\right)+\sum_{k=1}^{K-1} \boldsymbol{\Gamma}_{k} \boldsymbol{\Delta} \mathbf{p}_{t-k}+\mathbf{e}_{t}
$$

where $\mu=E\left(\boldsymbol{\beta}^{\prime} \mathbf{p}_{t-1}\right)$. The term $\mu$ in (2) captures systematic differences in the two prices, such as the mean bid-ask spread, or the risk free return between the spot and futures prices. The vector $\boldsymbol{\alpha}$ contains the error correction coefficients that measure each price's expected speed in eliminating the price difference ${ }^{3}$. The VEC model (2), in turn, is implied by the $K^{\text {th }}$ order vector autoregressive (VAR) model for price levels:

$$
\mathbf{p}_{t}=\mathbf{c}+\sum_{k=1}^{K} \mathbf{A}_{k} \mathbf{p}_{t-k}+\mathbf{e}_{t}
$$

where $\boldsymbol{\alpha} \boldsymbol{\beta}^{\prime}=-\mathbf{A}(1)=-\left(\mathbf{I}_{2}-\sum_{k=1}^{K} \mathbf{A}_{k}\right)$ and $\boldsymbol{\Gamma}_{k}=-\sum_{j=k+1}^{K} \mathbf{A}_{j}$.

Applying the Beveridge-Nelson (BN) decomposition (Beveridge and Nelson, 1981)

\footnotetext{
${ }^{3}$ Some papers in the price discovery literature (e.g. Harris et. al., 1995) interpret $\boldsymbol{\beta}^{\prime} \mathbf{p}_{t-1}$ as a lagged deviation from the asset's equilibrium value, and $\boldsymbol{\alpha}$ as the speed of adjustment to any deviation from the equilibrium. This interpretation, however, may extract more information than what the error correction model can accommodate. The $I(0)$ requirement on the cointegrating error $\boldsymbol{\beta}^{\prime} \mathbf{p}_{t-1}$ only implies that the price difference can not drift without bound. It doesn't identify the prices' positions relative to the unobserved equilibrium value. For example, $p_{1, t-1}$ and $p_{2, t-1}$ may be either well above or below the equilibrium and close to each other, so that $\boldsymbol{\beta}^{\prime} \mathbf{p}_{t-1}$ only measures the price difference. The price difference $\boldsymbol{\beta}^{\prime} \mathbf{p}_{t-1}$ may be interpreted as the deviation from the equilibrium only when one of the price variables follows a random walk. In this case, the random walk variable defines the trend or equilibrium and consequently eliminates the ambiguity in interpreting $\boldsymbol{\beta}^{\prime} \mathbf{p}_{t-1}$. However, this is a special case and should not be taken as a general rule.
} 
to $\boldsymbol{\Psi}(L)$ in (1) and iterating backward yields the levels relationship:

$$
\mathbf{p}_{t}=\mathbf{p}_{0}+\boldsymbol{\Psi}(1) \sum_{j=1}^{t} \mathbf{e}_{j}+\mathbf{s}_{t}
$$

where $\boldsymbol{\Psi}(1)=\sum_{k=0}^{\infty} \mathbf{\Psi}_{k}, \mathbf{s}_{t}=\left(s_{1, t}, s_{2, t}\right)^{\prime}=\boldsymbol{\Psi}^{*}(L) \mathbf{e}_{t}, \mathbf{\Psi}_{k}^{*}=-\sum_{j=k+1}^{\infty} \boldsymbol{\Psi}_{j}, \quad k=$ $0, \cdots, \infty$. Since the elements of $\left\{\boldsymbol{\Psi}_{k}\right\}_{k=0}^{\infty}$ are 1-summable, the elements of $\left\{\boldsymbol{\Psi}_{k}^{*}\right\}_{k=0}^{\infty}$ are also 1-summable which implies that $\mathbf{s}_{t} \sim I(0)$. The matrix $\boldsymbol{\Psi}(1)$ contains the cumulative impacts of the innovation $\mathbf{e}_{t}$ on all future price movements, and thus measures the long-run impact of $\mathbf{e}_{t}$ on prices. As shown in Hasbrouck (1995), since $\boldsymbol{\beta}^{\prime} \boldsymbol{\Psi}(1)=\mathbf{0}$ and $\boldsymbol{\beta}=(1,-1)^{\prime}$, the rows of $\boldsymbol{\Psi}(1)$ are identical. As a result, the long-run impacts of an innovation $\mathbf{e}_{t}$ on each of the prices are identical. Denote $\boldsymbol{\psi}=\left(\psi_{1}, \psi_{2}\right)^{\prime}$ as the common row vector of $\boldsymbol{\Psi}(1)$ and define the permanent innovation:

$$
\eta_{t}^{P}=\boldsymbol{\psi}^{\prime} \mathbf{e}_{t}=\psi_{1} e_{1, t}+\psi_{2} e_{2, t}
$$

We may then rewrite (3) as the common stochastic trend representation suggested in Stock and Watson (1988)

$$
\begin{aligned}
\mathbf{p}_{t} & =\mathbf{p}_{0}+\left[\begin{array}{l}
1 \\
1
\end{array}\right] m_{t}+\mathbf{s}_{t} \\
m_{t} & =m_{t-1}+\eta_{t}^{P} \\
\mathbf{s}_{t} & =\mathbf{\Psi}^{*}(L) \mathbf{e}_{t}
\end{aligned}
$$

Equation (5) shows that each of the cointegrated prices for the same underlying asset is composed of an unobservable, common fundamental full-information value $m_{t}$, a transitory pricing error $s_{i, t}$ in market $i$, and a constant. The common trend, defined as the efficient price in Hasbrouck (1995), evolves as a random walk driven by new information on the asset's future value, and is the driving force of the cointegrated prices. The pricing error $s_{i, t}$ captures any deviation of the price from its current, 
unobservable efficient price. It may arise from trading related frictions, such as the bid-ask bounce and rounding effects, and lagged adjustment to new information. Finally, the remaining constant reflects any nonstochastic difference between the price and its efficient price, e.g. the average (half) bid-ask spread or the initial value. For simplicity, in what follows assume $\mathbf{p}_{0}$ is equal to the zero vector ${ }^{4}$.

\subsection{Information Share}

The innovation $\eta_{t}^{P}$ to the common efficient price in (5) impounds new information about the asset's fundamental value and has a permanent impact on the price levels. Hasbrouck (1995) proposes a measure for one market's contribution to price discovery based on the share of the variance of $\eta_{t}^{P}$ that is attributable to this market. From (4), the variance of $\eta_{t}^{P}$ is $\boldsymbol{\psi}^{\prime} \boldsymbol{\Sigma} \boldsymbol{\psi}$. If $\boldsymbol{\Sigma}$ is diagonal, i.e. the reduced form VEC errors are uncorrelated, then market $i$ 's information share (IS) is defined as:

$$
\mathrm{IS}_{i}=\frac{\psi_{i}^{2} \sigma_{i}^{2}}{\psi^{\prime} \boldsymbol{\Sigma} \boldsymbol{\psi}}=\frac{\psi_{i}^{2} \sigma_{i}^{2}}{\psi_{1}^{2} \sigma_{1}^{2}+\psi_{2}^{2} \sigma_{2}^{2}}, \quad i=1,2
$$

where $\psi_{i}$ is the $i$ th element of $\boldsymbol{\psi}$, and $\sigma_{i}^{2}$ is the $i$ th diagonal element in $\boldsymbol{\Sigma}$. By construction, $\mathrm{IS}_{1}+\mathrm{IS}_{2}=1$. From (6), it is clear that a low (high) information share for market $i$ implies a small (large) reaction to the arrival of new information about fundamental value.

If $\boldsymbol{\Sigma}$ is non-diagonal, the IS measure has the problem of attributing the covariance terms to each market. Hasbrouck suggests to compute the Cholesky decomposition of $\boldsymbol{\Sigma}$ and measure the IS using the orthogonalized innovations. Let $\mathbf{F}$ be a lower triangular matrix such that $\mathbf{F F}^{\prime}=\boldsymbol{\Sigma}$. Then the IS for the $i$ th market is

$$
\mathrm{IS}_{i}=\frac{\left(\left[\boldsymbol{\psi}^{\prime} \mathbf{F}\right]_{i}\right)^{2}}{\boldsymbol{\psi}^{\prime} \mathbf{\Sigma} \boldsymbol{\psi}}
$$

\footnotetext{
${ }^{4}$ The common trends representation (5) is often used as the starting point for stylized models of price discovery (e.g. Hasbrouck 1995, and Harris et. al. 2002). However, interpretation problems immediately arise because the innovations $\eta_{t}^{P}$ and $\mathbf{s}_{t}$ may be correlated.
} 
where $\left[\boldsymbol{\psi}^{\prime} \mathbf{F}\right]_{i}$ is the $i$ th element of the row matrix $\boldsymbol{\psi}^{\prime} \mathbf{F}$. The resulting IS depends on the ordering of price variables. In the bivariate case, the upper (lower) bound of the $\mathrm{IS}_{i}$ is obtained by computing the Cholesky factorization with the $i$ th price ordered first (last). With $n$ prices, Hasbrouck (2002) shows that one must examine all permutations of the variables.

For empirical implementations, Hasbrouck (1995, 2003) suggests sampling at very high frequencies to reduce the contemporaneous correlation in the reduced form residuals between markets that is created by time aggregation. The hope is that sampling at high frequencies exposes the sequential operation of markets so that the IS can accurately measure which market moves first in response to new information. However, it is well known (e.g. Andersen et. al. 2002) that sampling too frequently runs the risk of contaminating the data with transitory microstructure noise. Empirically, how often to sample prices to reduce residual correlation appears to be context specific. For example, in his study of determining the relative contribution to price discovery between the NYSE and regional exchanges, Hasbrouck used a sampling interval of one second which produced a low contemporaneous residual correlation and a narrow range of information shares. Tse et. al (2005) and Hendershott and Jones (2005) also sampled at one second and found low residual correlations in their studies of price discovery on electronic exchanges. Grammig et. al. (2005), who analyzed exchange rates along with equity quotes for three German firms trading on the NYSE and the XETRA, found little residual correlation when sampling at 10 seconds but substantial correlation when sampling at one minute. Theissen (2002), in his study of price discovery in floor-based and electronic exchanges using data from the German stock market, found accurate IS measures with one minute sampling but inaccurate measures using five minute sampling. In contrast, Sapp (2002) studied price discovery in DM-\$US dealer quotes and found little difference in IS values using 30 second or five minute sampling. Huang (2002), who studied the quote quality by ECN and NASDQ dealers, used a one minute sampling interval which produced a substantial 
contemporaneous residual correlation and wide upper and lower bounds for the IS. In general, if the contemporaneous residual correlation is large, it is not unusual for the lower bound of one market's IS to be lower than the upper bound of another market's IS making interpretation of the results difficult.

\subsection{Component Share}

Booth et. al. (1999), Chu et. al. (1999), and Harris et. al. (2002) propose using the permanent-transitory (PT) component decomposition of Gonzalo and Granger (1995) to measure a market's contribution to price discovery. The Gonzalo-Granger PT decomposition of $\mathbf{p}_{t}$ has the form

$$
\mathbf{p}_{t}=\mathbf{A}_{1} f_{t}+\mathbf{A}_{2} \mathbf{z}_{t}
$$

where $f_{t}$ is the permanent component, $\mathbf{z}_{t}$ is the transitory component, and $\mathbf{A}_{1}$ and $\mathbf{A}_{2}$ are loading matrices. The components $f_{t}$ and $\mathbf{z}_{t}$ are linear combinations of $\mathbf{p}_{t}$ such that $f_{t} \sim I(1), \mathbf{z}_{t} \sim I(0)$, and $\mathbf{z}_{t}$ does not Granger cause $f_{t}$ in the long run. In particular, Granger and Gonzalo define $f_{t}=\gamma^{\prime} \mathbf{p}_{t}$ and $\mathbf{A}_{1}=\boldsymbol{\beta}_{\perp}\left(\boldsymbol{\alpha}_{\perp}^{\prime} \boldsymbol{\beta}_{\perp}\right)^{-1}$, where $\boldsymbol{\gamma}=\left(\boldsymbol{\alpha}_{\perp}^{\prime} \boldsymbol{\beta}_{\perp}\right)^{-1} \boldsymbol{\alpha}_{\perp}^{\prime}, \boldsymbol{\alpha}_{\perp}$ and $\boldsymbol{\beta}_{\perp}$ are $2 \times 1$ vectors such that $\boldsymbol{\alpha}_{\perp}^{\prime} \boldsymbol{\alpha}=0$ and $\boldsymbol{\beta}_{\perp}^{\prime} \boldsymbol{\beta}=0$. Since $\boldsymbol{\beta}=(1,-1)^{\prime}$, one choice for $\boldsymbol{\beta}_{\perp}$ is $\mathbf{1}=(1,1)^{\prime}$ implying $\boldsymbol{\gamma}=\left(\boldsymbol{\alpha}_{\perp}^{\prime} \mathbf{1}\right)^{-1} \boldsymbol{\alpha}_{\perp}^{\prime}$ so that the permanent component is a weighted average of observed prices with component weights $\gamma_{i}=\alpha_{\perp, i} /\left(\alpha_{\perp, 1}+\alpha_{\perp, 2}\right)$ for $i=1,2^{5}$. As a result, Booth et. al. (1999), Chu et. al. (1999), and Harris et. al. (2002) suggest measuring price discovery in market $i$ using the component share (CS)

$$
\mathrm{CS}_{i}=\frac{\alpha_{\perp, i}}{\alpha_{\perp, 1}+\alpha_{\perp, 2}}, i=1,2
$$

\footnotetext{
${ }^{5}$ In general, $\boldsymbol{\beta}_{\perp}=c \cdot \mathbf{1}$ where $c \neq 0$.Therefore setting $\boldsymbol{\beta}_{\perp}=\mathbf{1}$ imposes a particular normalization. However, the choice of normalization does not matter since the normalizing constant $c$ cancels when forming $\mathrm{CS}_{i}$.
} 
From (9), it is clear that a small (large) value of $\mathrm{CS}_{i}$ is directly related to a small (large) contribution of market $i$ to the Granger-Gonzalo permanent component of prices $f_{t}$. However, as shown by Granger and Gonzalo, the innovations to the permanent component $f_{t}$ are generally not serially uncorrelated and so are different from the efficient price innovations $\eta_{t}^{P}$ defined by (4). Therefore, the relationship between $\mathrm{CS}_{i}$ and $\mathrm{IS}_{i}$ is not immediately apparent. One advantage of the CS over the IS is its unique determination of a market's price discovery contribution.

Baillie et. al. (2002) and De Jong (2002) show that the vector of permanent component weights $\gamma$ in the Granger-Gonzalo PT decomposition and the vector of long-run impact coefficients $\boldsymbol{\psi}$ that make up the efficient price innovation (4) are equal up to a scale factor. This can be seen directly from Johansen's (1991) decomposition

$$
\boldsymbol{\Psi}(1)=\boldsymbol{\beta}_{\perp}\left(\boldsymbol{\alpha}_{\perp}^{\prime} \boldsymbol{\Gamma}(1) \boldsymbol{\beta}_{\perp}\right)^{-1} \boldsymbol{\alpha}_{\perp}^{\prime}=\boldsymbol{\xi} \boldsymbol{\alpha}_{\perp}^{\prime}
$$

where $\boldsymbol{\xi}=\boldsymbol{\beta}_{\perp}\left(\boldsymbol{\alpha}_{\perp}^{\prime} \boldsymbol{\Gamma}(1) \boldsymbol{\beta}_{\perp}\right)^{-1}$ and $\boldsymbol{\Gamma}(1)=\mathbf{I}_{2}-\sum_{j=1}^{K-1} \boldsymbol{\Gamma}_{j}$. From (10), the permanent innovation $\eta_{t}^{P}$ from (4) may also be defined as $\boldsymbol{\alpha}_{\perp}^{\prime} \mathbf{e}_{t}^{6}$. Since a one unit increase in $\eta_{t}^{P}$ has a one unit long-run impact on both prices it follows that $\boldsymbol{\xi}=\mathbf{1}$ and $\boldsymbol{\alpha}_{\perp}=\boldsymbol{\psi}$. Therefore, $\boldsymbol{\gamma}=\left(\boldsymbol{\psi}^{\prime} \mathbf{1}\right)^{-1} \boldsymbol{\psi}$. As a result, the CS measures may also be defined in terms of the elements of $\boldsymbol{\psi}$ as

$$
\mathrm{CS}_{i}=\frac{\psi_{i}}{\psi_{1}+\psi_{2}}, i=1,2
$$

The representation of CS in (11) shows that the two price discovery measures are closely related and present different views of price discovery. In particular, IS is a variance weighted version of CS when market innovations are uncorrelated.

Baillie et. al. (2002) note that since $\boldsymbol{\alpha}_{\perp}^{\prime} \boldsymbol{\alpha}=0$, (9) may also be expressed in terms of the elements of the error correction coefficient vector $\boldsymbol{\alpha}$. To see this, let $\boldsymbol{\alpha}=\left(\alpha_{1}, \alpha_{2}\right)^{\prime}$ and $\boldsymbol{\alpha}_{\perp}=\left(\alpha_{\perp, 1}, \alpha_{\perp, 2}\right)^{\prime}$. Then, $\boldsymbol{\alpha}_{\perp}^{\prime} \boldsymbol{\alpha}=\alpha_{\perp, 1} \alpha_{1}+\alpha_{\perp, 2} \alpha_{2}=0$ implies

\footnotetext{
${ }^{6}$ This is the permanent innovation defined in the Stock and Watson (1988) common trends representation and in the Gonzalo and $\mathrm{Ng}$ (2001) permanent-transitory decomposition.
} 
that $\alpha_{\perp, 1}=-\alpha_{\perp, 2} \alpha_{2} / \alpha_{1}$ and so (9) may be reexpressed as

$$
\mathrm{CS}_{1}=\frac{\alpha_{2}}{\alpha_{2}-\alpha_{1}}, \mathrm{CS}_{2}=\frac{-\alpha_{1}}{\alpha_{2}-\alpha_{1}}
$$

The representation (12) was originally derived by Schwarz and Szakmary (1994) using informal arguments. Interestingly, (12) shows that price discovery occurs entirely in market $i$ if $\alpha_{i}=0$; that is, if the contemporary price change in market $i$ does not respond to the lagged disequilibrium error $\boldsymbol{\beta}^{\prime} \mathbf{p}_{t-1}=p_{1 t-1}-p_{2 t-1}{ }^{7}$. Using (8) and the fact that $\boldsymbol{\beta}^{\prime} \mathbf{A}_{1}=0$, Booth et. al. (1999) note that $\boldsymbol{\beta}^{\prime} \mathbf{p}_{t-1}=\boldsymbol{\alpha} \boldsymbol{\beta}^{\prime} \mathbf{A}_{2} \mathbf{z}_{t-1}$ and argue that the error correction coefficients measure the way in which prices adjust to lagged differences in their transitory components. In this respect, the CS for market 1 reflects how sensitive market 2 is, relative to market 1 , to lagged transitory shocks and vice-versa.

In the two market framework, the CS may be equivalently represented in terms of the elements of $\boldsymbol{\psi}, \boldsymbol{\alpha}$ or $\boldsymbol{\alpha}_{\perp}$. The same is true for the IS. Martens (1998), Baillie et. al. (2002), and Theissen (2002) provide formulas for the IS based on $\boldsymbol{\alpha}$ or $\boldsymbol{\alpha}_{\perp}$ and the elements of the Cholesky factorization of the reduced form $\operatorname{VEC}(K-1)$ covariance matrix.

\section{Structural Price Discovery Cointegration Model}

As emphasized by Lehmann (2002), because the IS and CS measures of price discovery are based on the residuals from a reduced from VEC model their interpretation is not always clear. A clear interpretation of price discovery is only possible in a structural model; i.e., in a model in which the sources of shocks are identified. In this section, we propose a simple structural cointegration model for prices in arbitraged linked markets that identifies permanent and transitory shocks with minimal restrictions.

\footnotetext{
${ }^{7}$ This interpretation of $\mathrm{CS}_{i}$ links price discovery in market $i$ with the concept of weak exogeneity of prices for the cointegrating parameters in market $i$. See Zivot (2000) for a discussion of weak exogeneity in error correction models.
} 
Our model is motivated by the structural VAR models widely used in empirical macroeconomics (e.g. Bernanke 1986, Blanchard and Quah 1989, and King, Plosser, Stock and Watson 1991). An excellent survey of these models, which we draw heavily from, is given in Levtchenkova, Pagan and Robertson (1999).

We start with the following structural moving average (SMA) representation for the price changes in multiple markets

$$
\begin{aligned}
\Delta \mathbf{p}_{t} & =\mathbf{D}(L) \boldsymbol{\eta}_{t}=\mathbf{D}_{0} \boldsymbol{\eta}_{t}+\mathbf{D}_{1} \boldsymbol{\eta}_{t-1}+\mathbf{D}_{2} \boldsymbol{\eta}_{t-2}+\cdots \\
\mathbf{D}(L) & =\sum_{k=0}^{\infty} \mathbf{D}_{k} L^{k}, \mathbf{D}_{0} \neq \mathbf{I}_{2}
\end{aligned}
$$

where the elements of $\left\{\mathbf{D}_{k}\right\}_{k=0}^{\infty}$ are 1-summable and $\mathbf{D}_{0}$ is invertible. We assume that the number of structural shocks is equal to the number of observed prices, so that $\mathbf{D}(L)$ is invertible. Since $\mathbf{p}_{t}$ is cointegrated, one shock is labeled permanent and the other is labeled transitory so that $\boldsymbol{\eta}_{t}=\left(\eta_{t}^{P}, \eta_{t}^{T}\right)^{\prime}$. These structural shocks are assumed to be serially and mutually uncorrelated with diagonal covariance matrix $\operatorname{diag}\left(\sigma_{P}^{2}, \sigma_{T}^{2}\right)$. The matrix $\mathbf{D}_{0}$ contains the initial impacts of the structural shocks on $\Delta \mathbf{p}_{t}$, and defines the contemporaneous correlation structure of $\Delta \mathbf{p}_{t}$. Given the dichotomy into permanent and transitory shocks, the SMA model may be re-expressed equation-by-equation as

$$
\left(\begin{array}{c}
\Delta p_{1 t} \\
\Delta p_{2 t}
\end{array}\right)=\left(\begin{array}{ll}
d_{1}^{P}(L) & d_{1}^{T}(L) \\
d_{2}^{P}(L) & d_{2}^{T}(L)
\end{array}\right)\left(\begin{array}{c}
\eta_{t}^{P} \\
\eta_{t}^{T}
\end{array}\right)
$$

where $d_{i}^{P}(L)$ and $d_{i}^{T}(L)(i=1,2)$ are lag polynomials describing the dynamic responses to the permanent and transitory shocks, respectively.

As in (5), the permanent innovation $\eta_{t}^{P}$ is interpreted as new information on the fundamental value of the underlying asset, and permanently moves the market prices. The defining characteristic of $\eta_{t}^{P}$ is that it has a one-to-one long-run effect on the 
expected price levels for each asset:

$$
\lim _{k \rightarrow \infty} \frac{\partial E_{t}\left[\mathbf{p}_{t+k}\right]}{\partial \eta_{t}^{P}}=\lim _{k \rightarrow \infty} \sum_{l=0}^{k} \frac{\partial E_{t}\left[\Delta \mathbf{p}_{t+l}\right]}{\partial \eta_{t}^{P}}=\lim _{k \rightarrow \infty} \sum_{l=0}^{k} \mathbf{D}_{l}^{P}=\mathbf{D}^{P}(1)=\mathbf{1}
$$

where $\mathbf{D}_{k}^{P}$ and $\mathbf{D}^{P}(1)$ are the first column of the dynamic multiplier matrix $\mathbf{D}_{k}$ and the long-run impact matrix $\mathbf{D}(1)$ that corresponds to $\eta_{t}^{P}$, respectively. Equation (14) is similar to the identifying condition for the permanent innovation used by Gonzalo and Granger (1995) that defines the permanent innovation as having a nonzero long-run effect of the level of variables. Economic considerations further restrict the long-run effect to be a vector of ones, since a one unit increase in the fundamental value of one asset eventually cause the multiple market prices for the same asset to increase by one unit.

The transitory innovation $\eta_{t}^{T}$ summarizes all non-information related frictions, such as the trading by uninformed or liquidity traders, inventory adjustments, and temporary order imbalances. The defining characteristic of $\eta_{t}^{T}$ is that it has no longrun effect on the expected price levels:

$$
\lim _{k \rightarrow \infty} \frac{\partial E_{t}\left[\mathbf{p}_{t+k}\right]}{\partial \eta_{t}^{T}}=\lim _{k \rightarrow \infty} \sum_{l=0}^{k} \frac{\partial E_{t}\left[\Delta \mathbf{p}_{t+l}\right]}{\partial \eta_{t}^{T}}=\lim _{k \rightarrow \infty} \sum_{l=0}^{k} \mathbf{D}_{l}^{T}=\mathbf{D}^{T}(1)=\mathbf{0}
$$

where $\mathbf{D}_{k}^{T}$ and $\mathbf{D}^{T}(1)$ are the second column of the dynamic multiplier matrix $\mathbf{D}_{k}$ and the long-run impact matrix $\mathbf{D}(1)$ that corresponds to $\eta_{t}^{T}$, respectively. Hence, the long-run impact matrix of the structural innovations $\boldsymbol{\eta}_{t}$ has the form

$$
\mathbf{D}(1)=\left[\begin{array}{ll}
1 & 0 \\
1 & 0
\end{array}\right]
$$


Using (16), the BN decomposition of the SMA model in (13) is

$$
\begin{aligned}
\mathbf{p}_{t} & =\mathbf{p}_{0}+\mathbf{D}(1) \sum_{j=1}^{t} \boldsymbol{\eta}_{j}+\mathbf{s}_{t} \\
& =\left[\begin{array}{l}
1 \\
1
\end{array}\right] \sum_{j=1}^{t} \eta_{j}^{P}+\mathbf{s}_{t} \\
& =\left[\begin{array}{l}
1 \\
1
\end{array}\right] m_{t}+\mathbf{s}_{t}
\end{aligned}
$$

where $\mathbf{s}_{t}=\mathbf{D}^{*}(L) \boldsymbol{\eta}_{t}, \mathbf{D}_{k}^{*}=-\sum_{j=k+1}^{\infty} \mathbf{D}_{j}, k=0, \cdots, \infty$, and $m_{t}=m_{t-1}+\eta_{t}^{P}$. Equation (17) shows that the SMA model implies the same common efficient price representation for the multiple market prices as in the reduced form MA model (5), and the permanent innovation $\eta_{t}^{P}$ in the structural VMA model is the same as the efficient price innovation defined in (4). The only difference is that the transitory pricing errors $\mathbf{s}_{t}$ in (17) are now driven by the structural innovations $\boldsymbol{\eta}_{t}$. This implies that some of the pricing errors may be related to the arrival of new information, $\eta_{t}^{P}$, which includes, among others, the liquidity effect of information related trading and the lagged price adjustment to new information. Equation (17) also suggests that, although the multiple market prices share the common efficient price, the pricing errors in diverse markets may have different temporal responses to new information.

Yan and Zivot (2006) show that the parameters of the SMA model (13) may be uniquely identified from the parameters of the reduced form VEC model (2) using a modification of Gonzalo and Ng's (2001) permanent-transitory decomposition. The permanent shock is defined as $\eta_{t}^{P}=\boldsymbol{\psi}^{\prime} \mathbf{e}_{t}$ and the transitory shock $\eta_{t}^{T}$ is defined from $\tilde{\eta}_{t}^{T}=\boldsymbol{\beta}^{\prime} \mathbf{e}_{t}$ such that $\eta_{t}^{T}$ is orthogonal to $\eta_{t}^{P}$. This decomposition uniquely defines $\mathbf{D}_{0}$ and the remaining SMA parameters may be recovered from the relationship $\mathbf{D}(L)=$ $\boldsymbol{\Psi}(L) \mathbf{D}_{0}$.

We emphasize that minimal assumptions have been imposed on the SMA model 
specification (13). Only the long-run impacts of the structural innovations are specified. How the market prices respond overtime to new information and frictional factors is left unrestricted. Therefore, the model is general enough to accommodate various complex market microstructure effects.

\subsection{Examples of Structural Models}

To illustrate the SMA representation for a stylized market microstructure model, suppose the price $p_{i, t}$ in market $i(i=1,2)$ follows

$$
\begin{aligned}
p_{i, t} & =m_{t}+s_{i, t} \\
m_{t} & =m_{t-1}+\eta_{t}^{P} \\
s_{i, t} & =b_{0, i}^{P} \eta_{t}^{P}+b_{0, i}^{T} \eta_{t}^{T} \\
\boldsymbol{\eta}_{t} & =\left(\eta_{t}^{P}, \eta_{t}^{T}\right)^{\prime} \sim i . i . d . N\left(\mathbf{0},\left[\begin{array}{cc}
\sigma_{P}^{2} & 0 \\
0 & \sigma_{T}^{2}
\end{array}\right]\right)
\end{aligned}
$$

where $\eta_{t}^{P}$ is the informational innovation, $\eta_{t}^{T}$ captures transitory market frictions, $m_{t}$ is the efficient price common to the two markets, and $s_{i, t}$ is the pricing error in market $i$ due to trading frictions. This model, which we call model 1 , is similar to the structural model used by Lehmann (2002) to illustrate various aspects of price discovery measures. In (18), the pricing errors $s_{i, t}$ are partially due to the frictions by the information-related trading captured by $b_{0, i}^{P}$, and partially due to the frictions by the non-information related trading captured by $b_{0, i}^{T}$. Since the trading direction, hitting the offer or taking the bid, is likely to be positively correlated with the nature of the new information in $\eta_{t}^{P}$, good or bad, $b_{0,1}^{P}$ and $b_{0,2}^{P}$ are both expected to be positive. Because $\eta_{t}^{T}$ is the non-information related innovation, it simply causes

divergence between the two market prices so that $b_{0,1}^{T}$ and $b_{0,2}^{T}$ are expected to have opposite signs. Without loss of generality, it is assumed that $b_{0,1}^{T}>0$ and $b_{0,2}^{T}<0$. Unlike the standard model in Glosten (1987), however, the model in (18) does not 
distinguish between public information and private information. Instead, the two types of new information are grouped into the efficient price permanent innovation, $\eta_{t}^{P}$, and they both impact the pricing error through trading frictions. Although a separate specification of the private and public information would allow a richer interpretation of the model, there are several reasons for the above specification in the price discovery analysis context. First, the main objective of price discovery studies is to examine and compare each market's information processing efficiency, where the new information is a statistical construct based on a subset of market information. The analysis is not intended to answer the question of where new information enters the market or where informed traders might choose to trade. Furthermore, while it is well accepted that private information enters the market when informed traders trade, the theoretical finance literature conventionally assumes that public information will become a part of the efficient price with no necessity of trading. In reality, however, while the public news release itself, say the US monthly unemployment report, is common knowledge, the exact quantitative impact of the public news on the asset's fundamental value may not be common knowledge immediately following the release. It is the trading or voting process among market participants that determines or discovers a market-wide agreed upon or "true" quantitative impact of the public news. For example, Beaver (1968) argues that surges in trading activity following public releases of information reflect "a lack of consensus regarding the price". Therefore, it is not unreasonable to allow public information to generate trading frictions.

The representation for $\Delta p_{i, t}(i=1,2)$ from (18) is

$$
\begin{aligned}
\Delta p_{i, t} & =\Delta m_{t}+\Delta s_{i, t} \\
& =\left(1+b_{0, i}^{P}\right) \eta_{t}^{P}+b_{0, i}^{T} \eta_{t}^{T}-b_{0, i}^{P} \eta_{t-1}^{P}-b_{0, i}^{T} \eta_{t-1}^{T}
\end{aligned}
$$


which implies a SMA representation of the form (13) with

$$
\mathbf{D}_{0}=\left(\begin{array}{cc}
1+b_{0,1}^{P} & b_{0,1}^{T} \\
1+b_{0,2}^{P} & b_{0,2}^{T}
\end{array}\right), \mathbf{D}_{1}=\left(\begin{array}{cc}
-b_{0,1}^{P} & -b_{0,1}^{T} \\
-b_{0,2}^{P} & -b_{0,2}^{T}
\end{array}\right)
$$

and $\mathbf{D}_{k}=\mathbf{0}$ for $k>1$. Note that $\mathbf{D}(1)=\mathbf{D}_{0}+\mathbf{D}_{1}$ satisfies the long-run restriction specified by (16). Also, if $b_{0, i}^{P}>0$ then the initial impact of news is greater than the long-run impact.

As another example, consider an asymmetric structural model in which market 1 is a dominant market, and market 2 is a satellite market trading at the stale (lagged efficient) price. We modify the stylized model (18) to account for the lead-lag relationship between the two markets as follows:

$$
\begin{aligned}
p_{1, t} & =m_{t}+s_{1, t} \\
p_{2, t} & =m_{t-1}+s_{2, t} \\
m_{t} & =m_{t-1}+\eta_{t}^{P} \\
s_{i, t} & =b_{0, i}^{P} \eta_{t}^{P}+b_{0, i}^{T} \eta_{t}^{T}, i=1,2
\end{aligned}
$$

This model, which we call model 2, is similar to one used in Hasbrouck (1995). The price in Market 1 is based on the current efficient price, whereas the price in market 2 is based on the one-period lagged or stale efficient price. Straightforward calculations give the SMA representation with

$$
\mathbf{D}_{0}=\left(\begin{array}{cc}
1+b_{0,1}^{P} & b_{0,1}^{T} \\
b_{0,2}^{P} & b_{0,2}^{T}
\end{array}\right), \mathbf{D}_{1}=\left(\begin{array}{cc}
-b_{0,1}^{P} & -b_{0,1}^{T} \\
1-b_{0,2}^{P} & -b_{0,2}^{T}
\end{array}\right)
$$

and $\mathbf{D}(1)=\mathbf{D}_{0}+\mathbf{D}_{1}$ given by (16). The price response of market 1 to the informational innovation $\eta_{t}^{P}$ is $1+b_{0,1}^{P}$ in period $t$, and settles to its permanent one unit change in period $t+1$. The price response of market 2 to $\eta_{t}^{P}$ is $b_{0,2}^{P}$ at time $t$, and 
catches up to the permanent one unit change afterwards. The price responses of the two markets to the frictional innovation $\eta_{t}^{T}$ are $b_{0,1}^{T}$ and $b_{0,2}^{T}$ at period $t$, and 0 at period $t+1$, respectively.

As a final example model with more complicated dynamics, which we call model 3, consider a partial price adjustment model similar to that used in Amihud and Mendelson (1987) and Hasbrouck and Ho (1987):

$$
\begin{aligned}
p_{i t} & =p_{i t-1}+\delta_{i}\left(m_{t}-p_{i t-1}\right)+b_{0, i}^{T} \eta_{t}^{T} \\
m_{t} & =m_{t-1}+\eta_{t}^{P} \\
0 & \leq \delta_{i} \leq 2
\end{aligned}
$$

Solving for $\Delta p_{i t}$ gives

$$
\begin{aligned}
\Delta p_{i t} & =\left[1-\left(1-\delta_{i}\right) L\right]^{-1} \delta_{i} \eta_{t}^{P}+\left[1-\left(1-\delta_{i}\right) L\right]^{-1}(1-L) b_{0, i}^{T} \eta_{t}^{T} \\
& =d_{i}^{P}(L) \eta_{t}^{P}+d_{i}^{T}(L) \eta_{t}^{T}
\end{aligned}
$$

where $d_{i}^{P}(L)=\left[1-\left(1-\delta_{i}\right) L\right]^{-1} \delta_{i}$ and $d_{i}^{T}(L)=\left[1-\left(1-\delta_{i}\right) L\right]^{-1}(1-L) b_{0, i}^{T}$. The SMA representation (13) is determined from the appropriate elements of the lag polynomials $d_{i}^{P}(L)$ and $d_{i}^{T}(L)$. In particular, the initial impact and long-run impact matrices are given by

$$
\begin{aligned}
\mathbf{D}_{0} & =\left(\begin{array}{ll}
d_{1}^{P}(0) & d_{1}^{T}(0) \\
d_{2}^{P}(0) & d_{1}^{T}(0)
\end{array}\right)=\left(\begin{array}{ll}
\delta_{1} & b_{0,1}^{T} \\
\delta_{2} & b_{0,2}^{T}
\end{array}\right) \\
\mathbf{D}(1) & =\left(\begin{array}{ll}
d_{1}^{P}(1) & d_{1}^{T}(1) \\
d_{2}^{P}(1) & d_{1}^{T}(1)
\end{array}\right)=\left(\begin{array}{ll}
1 & 0 \\
1 & 0
\end{array}\right)
\end{aligned}
$$

Amihud and Mendelson (1987) used (20) with $b_{0, i}^{T}=1$ to model the dynamics of price adjustment to fundamental value for a single security. Hasbrouck and Ho (1987) 
used this model with $b_{0, i}^{T}=0$ to explain positive autocorrelations in stock returns. In the price discovery context, $\delta_{i}$ captures the speed of price discovery or information processing. Following a one unit change to the efficient price, in each period market $i^{\prime} s$ price will move toward, or discover, the new efficient price at rate of $\delta_{i}$. A value of

$\delta_{i}$ closer to one implies a more efficient price discovery process. If $\delta_{i}=1$ and $\eta_{t}^{T}=0$, then new information is immediately incorporated and the market price will be equal to the efficient price. If $\delta_{i}>1$ then overshooting of traders to new information occurs.

\section{Structural Interpretations of the IS and CS}

Price discovery measures are supposed to distinguish which market prices incorporate new information regarding fundamental value more quickly and efficiently. For example, Hasbrouck (1995) interprets the IS as measuring "who moves first in the process of price adjustment" and gives some simple examples in which the IS accurately reflects this interpretation. More recently, Baillie et. al (2002), Lehmann (2002) and Hasbrouck (2002) construct simple microstructure models with various price discovery lead-lag structures and provide a comparative analysis of the IS and CS. In some examples, the IS and CS give similar results and in other examples they differ considerably. However, the question of what the IS and CS actually measure in a structural dynamic model is complicated by the fact that these measures are defined in terms of the reduced form VEC innovations. Generally, reduced form innovations are best interpreted as forecasting errors, and are a mixture of various underlying structural innovations which may include new information (e.g. the efficient price innovation) and non-information related frictions (e.g. temporary order imbalances). Forecasting errors by themselves do not have clear structural interpretations except in some special circumstances. Therefore, to examine what is actually measured by the IS and CS and to provide a clear linkage between them, a structural analysis of the two measures in terms of the underlying structural parameters and innovations 
is necessary.

We give a structural interpretation of the IS and CS using the structural cointegration model described in the previous section. From (1) and (13), the reduced form forecasting errors, $\mathbf{e}_{t}$, are related to the structural innovations, $\boldsymbol{\eta}_{t}$, via the relation

$$
\mathbf{e}_{t}=\mathbf{D}_{0} \boldsymbol{\eta}_{t}=\left(\begin{array}{cc}
d_{0,1}^{P} & d_{0,1}^{T} \\
d_{0,2}^{P} & d_{0,2}^{T}
\end{array}\right)\left(\begin{array}{c}
\eta_{t}^{P} \\
\eta_{t}^{T}
\end{array}\right)
$$

where $\mathbf{D}_{0}$ is the structural initial impact matrix. Equation by equation, (21) becomes

$$
\begin{aligned}
& e_{1, t}=d_{0,1}^{P} \eta_{t}^{P}+d_{0,1}^{T} \eta_{t}^{T} \\
& e_{2, t}=d_{0,2}^{P} \eta_{t}^{P}+d_{0,2}^{T} \eta_{t}^{T}
\end{aligned}
$$

In (22), each of the forecasting errors can be attributed to the unobservable informational innovation $\eta_{t}^{P}$ and frictional innovation $\eta_{t}^{T}$. The parameters $d_{0, i}^{P}$ and $d_{0, i}^{T}$ $(i=1,2)$ are the contemporaneous responses of $p_{i, t}$ to the informational and frictional innovations, respectively.

Given that $\mathbf{D}_{0}$ is invertible, the structural errors may be expressed in terms of the reduced form errors via $\boldsymbol{\eta}_{t}=\mathbf{D}_{0}^{-1} \mathbf{e}_{t}$. Straightforward algebra then gives

$$
\begin{aligned}
\eta_{t}^{P} & =\frac{d_{0,2}^{T}}{\Delta} e_{1, t}-\frac{d_{0,1}^{T}}{\Delta} e_{2, t} \\
\eta_{t}^{T} & =-\frac{d_{0,2}^{P}}{\Delta} e_{1, t}+\frac{d_{0,1}^{P}}{\Delta} e_{2, t}
\end{aligned}
$$

where $\Delta=\left|\mathbf{D}_{0}\right|=d_{0,1}^{P} d_{0,2}^{T}-d_{0,1}^{T} d_{0,2}^{P}$. Since the permanent innovation, $\eta_{t}^{P}$, in the SMA model (13) is the same as the efficient price innovation, $\eta_{t}^{P}=\psi_{1} e_{1, t}+\psi_{2} e_{2, t}$, defined from the reduced form common trend model (4), the parameters $\psi_{1}$ and $\psi_{2}$ are linked to the initial impact structural parameters in $\mathbf{D}_{0}$ through

$$
\psi_{1}=\frac{d_{0,2}^{T}}{\Delta}, \psi_{2}=-\frac{d_{0,1}^{T}}{\Delta}
$$


Another way to derive (24) is to first note that $\mathbf{D}(L)=\mathbf{\Psi}(L) \mathbf{D}_{0}$ gives the relationship between the SMA polynomial matrix $\mathbf{D}(L)$ from (13) and the reduced form MA polynomial matrix $\boldsymbol{\Psi}(L)$ from (1). It follows that

$$
\mathbf{D}(1)=[\mathbf{1}: \mathbf{0}]=\mathbf{\Psi}(1) \mathbf{D}_{0}=\mathbf{1} \psi^{\prime} \mathbf{D}_{0}
$$

Therefore, the elements of $\boldsymbol{\psi}$ may be expressed in terms of the elements of $\mathbf{D}_{0}$ through the relation $\mathbf{D}(1) \mathbf{D}_{0}^{-1}=\mathbf{1} \boldsymbol{\psi}^{\prime}$. Straightforward algebra confirms (24).

While $\psi_{1}$ and $\psi_{2}$ are weights on the respective market forecasting errors used to define the efficient price innovation in (4) and used in the IS and CS to measure each market's contribution to discover new information, equation (24) reveals that they are, in fact, proportional to the markets' contemporaneous responses to the structural frictional innovation. This seemingly paradoxical result can be explained by the mixture nature of the forecasting errors (i.e., they contain both informational and frictional innovations) and the fact that the long-run structural impact parameters in $\mathbf{D}(1)$ are normalized to unity by assumption. When equation (4) extracts the permanent innovation $\eta_{t}^{P}$ from the reduced form forecasting errors $\mathbf{e}_{t}$, the transitory

innovation $\eta_{t}^{T}$ must be purged. It can be shown that it is the requirement to remove the frictional innovation that leads to the result in (24).

\subsection{Component Share}

We are now ready to consider the structural interpretation of the CS. Using (24), the structural representation of the CS for markets 1 and 2 is

$$
\mathrm{CS}_{1}=\frac{d_{0,2}^{T}}{d_{0,2}^{T}-d_{0,1}^{T}}, \quad \mathrm{CS}_{2}=\frac{-d_{0,1}^{T}}{d_{0,2}^{T}-d_{0,1}^{T}}
$$


provided $d_{0,2}^{T} \neq d_{0,1}^{T}{ }^{8}$. Surprisingly, (25) shows that the CS only involves the structural parameters governing the price responses to the frictional innovation. Instead of measuring the relative strength of how a given market price responds to new information $^{9}$, the CS measures the relative response to contemporaneous transitory frictions. In particular, $\mathrm{CS}_{1}$ will be higher than $\mathrm{CS}_{2}$ if market 2 responds more strongly to the transitory shock than market 1 . Moreover, it follows from (25) that $\mathrm{CS}_{1}=0$ only if $d_{0,2}^{T}=0$ and vice-versa. The structural representation of the CS in (25) is similar to reduced form representation (12) based on the error correction coefficients. In fact, (12) and (25) imply that the error correction coefficients $\alpha_{i}$ are proportional to the contemporaneous transitory impact parameters $d_{0, i}^{T}$. However, the interpretation is slightly different. In the reduced form representation (12), $\mathrm{CS}_{1}$ measures the relative lagged response of market 2 to the Granger-Gonzalo transitory components of the disequilibrium error $\boldsymbol{\beta}^{\prime} \mathbf{p}_{t}$.

To illustrate the structural representation of the CS, consider the three stylized microstructure models presented in subsection 3.1. Since the initial impacts of the transitory shocks are specified in the same way across the three models, application of (25) gives

$$
\mathrm{CS}_{1}=\frac{b_{0,2}^{T}}{b_{0,2}^{T}-b_{0,1}^{T}}, \mathrm{CS}_{2}=\frac{-b_{0,1}^{T}}{b_{0,2}^{T}-b_{0,1}^{T}}
$$

for all three models. As a further illustration, Table 1 gives two parameterizations of model 1 given by (18). The first row of the table gives the SMA representation of (18) with $b_{0,1}^{P}=b_{0,2}^{P}=0, b_{0,1}^{T}=0$ and $b_{0,2}^{T}=\varepsilon \neq 0$. In this case, both markets fully incorporate the impact of new information when it arrives. Market 1 does not respond to the transitory shock at all and its price is equal to the efficient price,

\footnotetext{
${ }^{8}$ Notice that the CS is not defined if $d_{0,2}^{T}=d_{0,1}^{T}$. In this case, $(24)$ shows that $\boldsymbol{\psi}^{\prime} \mathbf{1}=\psi_{1}+\psi_{2}=0$ so that $\boldsymbol{\psi}=\boldsymbol{\alpha}_{\perp}$ is orthogonal to $\mathbf{1}$. Since $\boldsymbol{\beta}=(1,-1)^{\prime}$ is also orthogonal to $\mathbf{1}$, it follows that $\boldsymbol{\alpha}_{\perp}^{\prime} \boldsymbol{\beta}_{\perp}=0$ which implies that there is no common permanent component in the vector of prices. In other words, $\boldsymbol{\beta}=(1,-1)^{\prime}$ cannot be a cointegrating vector if $d_{0,2}^{T}=d_{0,1}^{T}$. Also, if both markets react in the same way to the permanent and transitory shocks, then $\mathbf{D}_{0}$ is not invertible and these shocks cannot be separately identified from the data.

${ }^{9}$ Lehmann (2002) reaches the same conclusion based on the observation that the CS only involves the long-run impacts of the reduced form innovations on the prices.
} 
whereas $\varepsilon$ captures the contemporaneous impact of the transitory shock on market 2. From (26), we see that $\mathrm{CS}_{1}=1$ and $\mathrm{CS}_{2}=0$. This result holds even if $\varepsilon$ is arbitrarily close to zero. The second row of Table 1 gives the SMA representation with $b_{0,1}^{P}=\varepsilon-1, b_{0,2}^{P}=0$, and $b_{0,1}^{T}=-b_{0,2}^{T}=\delta \neq 0$. In this case, market 1 only incorporates the fraction $\varepsilon$ of the permanent shock in the initial period whereas market 2 fully incorporates the shock. Additionally, both markets respond equally (in absolute value) to the transitory shock. Using (26), it follows that $\mathrm{CS}_{1}=\mathrm{CS}_{2}=0.5$ regardless of the value of $\varepsilon$. These two examples illustrate situations in which the CS may give highly misleading information regarding the price discovery efficiency of a market.

\subsection{Information Share}

Now consider the structural interpretation of the IS. A full structural analysis of the IS is complicated by covariance structure of the reduced form forecasting errors. When the reduced form innovations, $\mathbf{e}_{t}$, are uncorrelated, the IS is supposed to give unambiguous results. This special case also allows for a clear structural interpretation of the IS using the structural cointegration model.

The relationship between the reduced form innovations and the structural innovations is given in (22). Since $\eta_{t}^{P}$ and $\eta_{t}^{T}$ are uncorrelated by assumption,

$$
\begin{aligned}
\operatorname{var}\left(e_{1 t}\right) & =\left(d_{0,1}^{P}\right)^{2} \sigma_{P}^{2}+\left(d_{0,1}^{T}\right)^{2} \sigma_{T}^{2} \\
\operatorname{var}\left(e_{2 t}\right) & =\left(d_{0,2}^{P}\right)^{2} \sigma_{P}^{2}+\left(d_{0,2}^{T}\right)^{2} \sigma_{T}^{2} \\
\operatorname{cov}\left(e_{1 t}, e_{2 t}\right) & =d_{0,1}^{P} d_{0,2}^{P} \sigma_{p}^{2}+d_{0,1}^{T} d_{0,2}^{T} \sigma_{T}^{2}
\end{aligned}
$$

There are three cases in which $\operatorname{cov}\left(e_{1 t}, e_{2 t}\right)=0$ and an unambiguous structural interpretation of IS can be made.

The first case occurs when $d_{0,2}^{P}=d_{0,1}^{T}=0$ and $d_{0,1}^{P} d_{0,2}^{T} \neq 0$ so that $e_{1 t}=d_{0,1}^{P} \eta_{t}^{P}$ and $e_{2 t}=d_{0,2}^{T} \eta_{t}^{T}$. Here, market 1 only responds contemporaneously to the permanent 
shock and market 2 only responds to the transitory shock. This case has the structure of the stale price model (19). Using (6) and (24), it follows that $\mathrm{IS}_{1}=1$ so that the IS correctly captures "who moves first" with respect to new information. Since $d_{0,1}^{T}=0$ it follows from $(25)$ that $\mathrm{CS}_{1}=1$ and so the IS and CS give the same results. The second case in which $\operatorname{cov}\left(e_{1 t}, e_{2 t}\right)=0$ occurs is when $d_{0,1}^{P}=d_{0,2}^{T}=0$ and $d_{0,2}^{P} d_{0,1}^{T} \neq 0$, so that only market 2 responds contemporaneously to the permanent shock. Here, $\mathrm{IS}_{2}=\mathrm{CS}_{2}=1$ and these measures again correctly capture "who moves first". These two cases correspond to Hasbrouck's explanation that sampling at high frequencies exposes the sequential operation of markets so that the IS can accurately measure which market moves first in response to new information

The third case in which $\operatorname{cov}\left(e_{1 t}, e_{2 t}\right)=0$ occurs is when

$$
\frac{\sigma_{T}^{2}}{\sigma_{P}^{2}}=\frac{d_{0,1}^{P} d_{0,2}^{P}}{-d_{0,1}^{T} d_{0,2}^{T}}
$$

and all elements of $\mathbf{D}_{0}$ are nonzero such that $\left|\mathbf{D}_{0}\right| \neq 0$. Using (27), (24) and (6), it can be shown (see Appendix) that

$$
\mathrm{IS}_{1}=\frac{d_{0,1}^{P} d_{0,2}^{T}}{\Delta}, \mathrm{IS}_{2}=\frac{-d_{0,1}^{T} d_{0,2}^{P}}{\Delta}
$$

where $\Delta=d_{0,1}^{P} d_{0,2}^{T}-d_{0,1}^{T} d_{0,2}^{P}$. In this case, the structural representation of the IS consists of contemporaneous responses to both permanent and transitory shocks. This result is in contrast to Hasbrouck's claim that the IS effectively ignores transient price disturbances (Hasbrouck 1995, page 1184). The expressions for the IS in (28) reduce to the expressions for the CS in (25) if $d_{1,0}^{P}=d_{2,0}^{P}$. In this case, both the IS and CS only depend on the contemporaneous impacts of the transitory shocks.

Compared with the structural representation of the CS in (25), the IS representation with uncorrelated residuals is more appropriate for measuring price discovery in that the IS for one market contains that market's response to new information. 
However, the presence of the frictional innovation's contemporaneous impact in (28) implies that the IS cannot always be interpreted without ambiguity. Specifically, a high IS value for one market due to the market's strong response to new information cannot be distinguished from a high IS value due to another market's strong response to frictions. That is, a high value for $\mathrm{IS}_{1}$ can be caused by a high value for $d_{0,1}^{P}$, a high value for $d_{0,2}^{T}$, or high values for both parameters. Hence, even in the presence of uncorrelated reduced form errors the IS, by itself, cannot always be interpreted without ambiguity. Additional information from the CS, however, may help to remove some of the ambiguity associated with the IS. Because the CS purely measures one market's response to transitory frictions relative to another market, a high IS accompanied with a low CS provides some evidence that a market has a relatively strong response to the informational innovation. A high IS together with a high CS would suggest otherwise.

Table 2 gives the IS values for the three stylized microstructure models presented in subsection 3.1 under the assumption that the reduced form errors are uncorrelated based on (27). In general, the IS cannot be interpreted without ambiguity for the three models. For example, in the stale price model (19), $\mathrm{IS}_{1}$ could be small if $\left|b_{0,1}^{T}\right|$ is very large relative to $\left|b_{0,2}^{T}\right|$. This situation can be uncovered by looking at $\left|\mathrm{CS}_{1} / \mathrm{CS}_{2}\right|=\left|b_{0,2}^{T} / b_{0,1}^{T}\right|$. Similarly, in the partial adjustment model (20), the market with the most efficient price discovery is the one in which $\delta_{i}$ is closest to 1 . However, the IS measures are confounded by the transitory impact parameters. As with the stale price model, the relative magnitude of the transitory impact parameters can be measured by the ratio of the CS measures.

As a final illustration of the structural interpretation of the IS, consider the parameterizations of the stylized model (18) given in Table 1 under the zero covariance restriction (27). For the first parameterization, since the initial impacts to the permanent shocks are the same the IS values are the same as the CS values and attribute all price discovery to the first market. For the second parameterization, $\mathrm{IS}_{1}=\frac{\varepsilon}{1+\varepsilon}$ 
and $\mathrm{IS}_{2}=\frac{1}{1+\varepsilon}$. If $\varepsilon \approx 0$ then market 1 does not have an immediate impact from the permanent shock and $\mathrm{IS}_{1} \approx 0$ and $\mathrm{IS}_{2} \approx 1$. In contrast, if $\varepsilon \approx 1$ then market 1 and market 2 react in the same way to the permanent shocks and $\mathrm{IS}_{1} \approx \mathrm{IS}_{2} \approx 0.5$.

\subsection{Simulation Example}

To illustrate the empirical relevance of the analytical results for the CS and IS in (25) and (28), we compare the estimated CS and IS to their true analytical values using simulated data from two parameterizations of the stylized partial adjustment microstructure model (20). For the first parameterization, we set $\delta_{1}=0.8, \delta_{2}=0.2$, $b_{0,1}^{T}=0.5$ and $b_{0,2}^{T}=-0.5$. Market 1 has a greater speed of price discovery than market 2, and both markets respond equally, in absolute value, to the transitory shocks. Using (27) with $\sigma_{P}^{2}=1$ and $\sigma_{T}^{2}=0.64$ removes the correlation between the reduced form residuals. From (25) and (28), the analytic values for the CS and IS for market 1 are $\mathrm{CS}_{1}=0.5$ and $\mathrm{IS}_{1}=0.8$, respectively. From (24), the analytic value for $\boldsymbol{\psi}=\boldsymbol{\alpha}_{\perp}$ is $(1,1)^{\prime}$ which implies that $\boldsymbol{\alpha}=\left(\alpha_{1},-\alpha_{1}\right)^{\prime}$. For the second parameterization, we set $\delta_{1}=0.8, \delta_{2}=0.2, b_{0,1}^{T}=0.9, b_{0,2}^{T}=-0.1, \sigma_{P}^{2}=1$ and $\sigma_{T}^{2}=1.778$. Here, market 1 responds more strongly to the contemporaneous transitory shock than market 2. The corresponding values for the CS and IS for market 1 are $\mathrm{CS}_{1}=0.1$ and $\mathrm{IS}_{1}=0.308$, respectively, and $\boldsymbol{\psi}=(0.385,3.462)^{\prime}$. Here, the low values of $\mathrm{CS}_{1}$ and $\mathrm{IS}_{1}$ indicate that market 1 responds more strongly to the contemporaneous transitory shock than market 2 and not that market 2 responds more strongly to the contemporaneous permanent shock.

Based on the specified parameters, we generate 1000 artificial samples of size 100, 250, 500, 750, 1000, 5000 and 10000 observations from the bivariate price system (20) assuming normally distributed errors. To mimic what a researcher would do in practice, we fit the reduced form $\operatorname{VEC}(K-1)$ model $(2)$ using ordinary least squares with the lag order of the system determined by minimizing the Bayesian Information Criterion (BIC). We then estimate the CS from (11) and the IS from 
(7) using the parameters of the fitted $\operatorname{VEC}(K-1)$ model. To estimate $\boldsymbol{\Psi}(1)$, we use the Johansen factorization (10) and the estimate of $\boldsymbol{\psi}$ is taken to be the common row of the estimate of $\boldsymbol{\Psi}(1)$. To estimate $\boldsymbol{\alpha}_{\perp}$ and $\boldsymbol{\beta}_{\perp}$ up to a scale factor, we use the normalized eigenvectors associated with the matrices $\boldsymbol{\alpha} \boldsymbol{\alpha}^{\prime}$ and $\boldsymbol{\beta} \boldsymbol{\beta}^{\prime}$, respectively.

The results of the experiments are summarized in Tables 3 - 5. For each experiment, the tables report estimates (averaged over the 1000 simulations) of some of the $\operatorname{VEC}(K-1)$ parameters $\left(\alpha_{1}, \alpha_{2}, K-1, \psi_{1}, \psi_{2}, \rho=\operatorname{cov}\left(e_{1 t}, e_{2 t}\right)\right)$ as well as the price discovery measures for market $1\left(\mathrm{IS}_{L, 1}, \mathrm{IS}_{U, 1}\right.$, and $\left.\mathrm{CS}_{1}\right)$ for various sample sizes. The results in Tables 3 and 4 show that the IS and CS are very accurately estimated for samples larger than 500 observations. For small sample sizes, the IS and CS tend to be underestimated with high variability across the simulations. Table 5 reports the results from an experiment in which 500 observations are simulated from the second parameterization of the partial adjustment model but the $\operatorname{VEC}(K-1)$ model (2) is estimated using data sampled at every $m$ th observation for $m=1,2, \ldots, 5$. This experiment is designed to illustrate the impact of high frequency transitory microstructure effects on the IS and CS when these measures are estimated using data sampled at different frequencies. At coarse sampling frequencies (e.g., $m=5$ ) there are severe biases in the $\operatorname{VEC}(K-1)$ parameter estimates, and the estimated residual correlation is large and positive. As a result, $\mathrm{IS}_{L, 1}$ is close to zero and $\mathrm{IS}_{U, 1}$ is close to one so that these estimates are not informative about price discovery. Interestingly, the CS estimates are not as badly biased as the IS estimates. As the sampling frequency approaches the true frequency $(m=1)$ the $\operatorname{VEC}(K-1)$ estimates become more accurate and the estimated residual correlation approaches zero. However, the IS estimates are still influenced by the contemporaneous transitory shock. The low values of $\mathrm{IS}_{1}$ and $\mathrm{CS}_{1}$ indicate that market 1 responds more strongly to the contemporaneous transitory shock than market 2 and not that market 2 responds more strongly to the contemporaneous permanent shock. 


\section{Conclusions}

Using a structural cointegration model, we investigate the structural determinants

of the information share and the component share - two widely used price discovery measures. We find that the two measures alone cannot distinguish the price discovery dynamics between markets. In particular, the component share does not reflect a market's price responses to new information at all, and the information share can not be interpreted unambiguously even when the cross-market innovations are uncorrelated. We show how the CS and IS may be used together to disentangle the impacts of permanent and transitory shocks. In addition, we show that the CS and IS are essentially static measures since they only account for contemporaneous price responses to the underlying structural innovations.

In a two market framework, our structural cointegration model can be used to define unambiguous measures of price discovery that capture the full dynamic process of how new information impacts prices. This is possible because the underlying structural shocks may be uniquely identified using a modification of the permanenttransitory decomposition of Gonzalo and $\mathrm{Ng}$ (2001). These new dynamic measures of price discovery are described and analyzed in detail in Yan and Zivot (2006). 


\section{Appendix}

From (22), it follows that

$$
\operatorname{var}\left(e_{1 t}\right)=\sigma_{1}^{2}=\left(d_{0,1}^{P}\right)^{2} \sigma_{P}^{2}+\left(d_{0,1}^{T}\right)^{2} \sigma_{T}^{2}
$$

and

$$
\operatorname{cov}\left(e_{1, t}, e_{2, t}\right)=d_{0,1}^{P} d_{0,2}^{P} \sigma_{P}^{2}+d_{0,1}^{T} d_{0,2}^{T} \sigma_{T}^{2}
$$

Assuming all elements of $\mathbf{D}_{0}$ are nonzero and $\left|\mathbf{D}_{0}\right| \neq 0$, the restriction $\operatorname{cov}\left(e_{1, t}, e_{2, t}\right)=$ 0 implies the result in $(27)$

$$
\frac{\sigma_{T}^{2}}{\sigma_{P}^{2}}=\frac{d_{0,1}^{P} d_{0,2}^{P}}{-d_{0,1}^{T} d_{0,2}^{T}}
$$

With uncorrelated reduced form VEC errors, the IS of market 1 is given by

$$
\mathrm{IS}_{1}=\frac{\psi_{1}^{2} \sigma_{1}^{2}}{\operatorname{var}\left(\eta_{t}^{P}\right)}
$$

Substituting (24) and (29) into (31) yields

$$
\begin{aligned}
\mathrm{IS}_{1} & =\frac{\left(d_{0,2}^{T}\right)^{2}}{\Delta^{2}} \times \frac{\left(d_{0,1}^{P}\right)^{2} \sigma_{P}^{2}+\left(d_{0,1}^{T}\right)^{2} \sigma_{T}^{2}}{\sigma_{P}^{2}} \\
& =\frac{\left(d_{0,2}^{T}\right)^{2}}{\Delta^{2}}\left[\left(d_{0,1}^{P}\right)^{2}+\left(d_{0,1}^{T}\right)^{2} \frac{\sigma_{T}^{2}}{\sigma_{P}^{2}}\right] \\
& =\frac{\left(d_{0,2}^{T}\right)^{2}}{\Delta^{2}}\left[\left(d_{0,1}^{P}\right)^{2}+\left(d_{0,1}^{T}\right)^{2} \frac{d_{0,1}^{P} d_{0,2}^{P}}{-d_{0,1}^{T} d_{0,2}^{T}}\right] \\
& =\frac{1}{\Delta^{2}}\left[\left(d_{0,1}^{P} d_{0,2}^{T}\right)^{2}-d_{0,2}^{T} d_{0,1}^{T} d_{0,1}^{P} d_{0,2}^{P}\right] \\
& =\frac{d_{0,1}^{P} d_{0,2}^{T}}{\Delta^{2}}\left[d_{0,1}^{P} d_{0,2}^{T}-d_{0,1}^{T} d_{0,2}^{P}\right] \\
& =\frac{d_{0,1}^{P} d_{0,2}^{T}}{\Delta}
\end{aligned}
$$

which verifies the result in (28). The derivation in (32) from the second to third line involves a substitution from (27), while the result in the last line is based on 
the definition of $\Delta$, the determinant of the $\mathbf{D}_{0}$ matrix. Because the ISs of the two markets are normalized to sum to 1 ,

$$
\begin{aligned}
\mathrm{IS}_{2} & =1-\mathrm{IS}_{1} \\
& =1-\frac{d_{0,1}^{P} d_{0,2}^{T}}{\Delta} \\
& =-\frac{d_{0,2}^{P} d_{0,1}^{T}}{\Delta}
\end{aligned}
$$




\section{References}

[1] Amihud, Y., and Haim Mendelson, 1987. Trading mechanisms and stock returns: an empirical investigation, Journal of Finance, 42, 533-555.

[2] Andersen, Torben G., Timmothy Bollerslev, and Frank X. Diebold, 2002. Parametric and nonparametric measurements of volatility, in Yacine Aït-Sahalia and Lars P. Hansen (Eds.) Handbook of Financial Econometrics, Elsevier NorthHolland. Forthcoming.

[3] Baillie, Richard T., G. Geoffrey Booth, Yiuman Tse, and Tatyana Zabotina, 2002. Price discovery and common factor models, Journal of Financial Markets $5,309-321$.

[4] Beaver, William H., 1968. The information content of annual earnings announcements, Empirical Research in Accounting: Selected Studies. Supplement to Journal of Accounting Research 6, 67-92.

[5] Bernanke, Ben, 1986. Alternative explanations of the money-income correlation, Carnegie-Rochester Conference Series on Public Policy, 25, 49-99.

[6] Beveridge, Stephen, and Charles R. Nelson, 1981. A new approach to the decomposition of economic time series into permanent and transitory components with particular attention to the measurement of the 'business cycle', Journal of Monetary Economics 7, 151-174.

[7] Blanchard, Olivier, and Danny Quah, 1989. The dynamic effects of aggregate demand and supply disturbances, American Economic Review, 79, 655-673.

[8] Booth, G. Geoffrey, Raymond W. So, and Yiuman Tse (1999). Price discovery in the German equity index derivatives markets, Journal of Futures Markets, 19, 619-643. 
[9] Chu, Q.C., W.G. Hsieh, and Yiuman Tse (1999). Price discovery on the S\&P 500 index markets: an analysis of spot index, index futures and SPDRs, International Review of Financial Analysis, 8, 21-34.

[10] De Jong, Frank, 2002, Measures of contributions to price discovery: a comparison. Journal of Financial Markets 5. 323-327.

[11] Engle, Robert F., and Clive Granger, 1987. Co-integration and error correction: Representation, estimation, and testing, Econometrica 55, 251-276.

[12] Glosten, Lawrence R., 1987. Components of the bid-ask spread and the statistical properties of transaction prices, Journal of Finance 42, 1293-1307.

[13] Gonzalo, Jesús, and Clive Granger, 1995. Estimation of common long-memory components in cointegrated systems. Journal of Business and Economic Statistics, 13, 27-35.

[14] Gonzalo, Jesús, and Serena Ng, 2001. A systematic framework for analyzing the dynamic effects of permanent and transitory shocks, Journal of Economic Dynamics and Control 25. 1527-1546.

[15] Grammig, Joachim, Michael Melvin, and Christian Schlag, 2005. Internationally cross-listed stock prices during overlapping trading hours: price discovery and exchange rate effects. Journal of Empirical Finance, 12, 139-164.

[16] Hamilton, James D., 1994. Time Series Analysis, Princeton University Press.

[17] Harris, Frederick H. deB., Thomas H. McInish, Gary L. Shoesmith, and Robert A. Wood, 1995. Cointegration, error correction, and price discovery on informationally linked security markets, Journal of Financial and Quantitative Analysis $30,563-579$. 
[18] Harris, Frederick H. deB., Thomas H. McInish, and Robert A. Wood, 2002. Security price adjustment across exchanges: an investigation of common factor components for Dow stocks. Journal of Financial Markets 5, 277-308.

[19] Hasbrouck, Joel, and Thomas S. Y. Ho, 1987. Order arrival, quote behavior, and the return-generating process, Journal of Finance 42, 1035-1048.

[20] Hasbrouck, Joel, 1995. One security, many markets: Determining the contributions to price discovery, Journal of Finance 50, 1175-1199.

[21] Hasbrouck, Joel, 2002. Stalking the "efficient price" in market microstructure specifications: an overview, Journal of Financial Markets 5, 329-339.

[22] Hasbrouck, Joel, 2003. Intraday price formation in U.S. equity index markets, Journal of Finance 58, 2375-2400.

[23] Hendershott, Terrence, and Charles M. Jones, 2005. Island goes dark: transparancy, fragmentation, and regulation. The Review of Financial Studies, $18,743-793$.

[24] Huang, Roger D., 2002. The quality of ECN and Nasdaq Market Maker Quotes, Journal of Finance 57, 1285-1319.

[25] Johansen, Soren, 1991. Estimation and Hypothesis Testing of Cointegration Vectors in Gaussian Vector Autoregressive Models, Econometrica, 59, 1551-1580.

[26] King, Robert G., Charles I. Plosser, James H. Stock, and Mark W. Watson 1991. Stochastic trends and economic fluctuations, American Economic Review, $81,819-840$.

[27] Lehmann, Bruce N., 2002. Some desiderata for the measurement of price discovery across markets, Journal of Financial Markets 5, 259-276. 
[28] Levtchenkova, S., A. Pagan, and J. Robertson, 1999. Shocking stories, in M. McAleer and L. Oxley eds. Practical Issues in Cointegration Analysis, Basil Blackwell: Oxford.

[29] Martens, Martin, 1998. Price discovery in high and low volatility periods: open outcry versus electronic trading. Journal of International Financial Markets, Institutions and Money, 8, 243-260.

[30] Sapp, Stephen, 2002. Price leadership in the spot foreign exchange market. Journal of Financial and Quantitative Analysis, 37, 425-448.

[31] Schwarz, Th., and Andrew Szakmary, 1994. Price discovery in petroleum markets: arbitrage, cointegration, and the time interval of analysis. Journal of $\mathrm{Fu}$ tures Markets, 14, 147-167.

[32] Stock, James H., and Mark W. Watson. 1988, Testing for common trends, Journal of the American Statistical Association 83, 1097-1107.

[33] Theissen, Eric, 2002. Price discovery in floor and screen trading systems. Journal of Empirical Finance, 9, 455-474.

[34] Tse, Yiuman, Paramita Bandyopadhyay, and Yang-Pin Shen, 2005. Intraday price discovery in the DJIA index markets, Journal of Business Finance $\mathcal{G}^{3}$ Accounting, 33, 1572-1585.

[35] Watson, Mark W, 1994. Vector autoregressions and cointegration, in Engle, Robert .F., and Daniel. L. McFadden (eds.), Handbook of Econometrics, 4, ch. $47,2843-2915$.

[36] Yan, Bingchen, and Eric Zivot (2006). The dynamics of price discovery, unpublished manuscript, Department of Economics, University of Washington.

[37] Zivot, Eric (2000). The power of single equation tests for cointegration when the cointegrating vector is prespecified, Econometric Theory, 16, 407-439. 


\section{Table 1: CS and IS from Stylized Structural Models}

This table reports the analytical results of the information share (IS) and component share (CS) based on two parameterizations of the following 2-market model:

$$
\begin{aligned}
p_{i, t} & =m_{t}+s_{i, t} \\
m_{t} & =m_{t-1}+\eta_{t}^{P} \\
s_{i, t} & =b_{0, i}^{P} \eta_{t}^{P}+b_{0, i}^{T} \eta_{t}^{T}
\end{aligned}
$$

where the structural errors $\boldsymbol{\eta}_{t}=\left(\eta_{t}^{P}, \eta_{t}^{T}\right)$ are normally distributed with zero means, diagonal covariance matrix $\operatorname{diag}\left(\sigma_{P}^{2}, \sigma_{T}^{2}\right)$, and are mutually uncorrelated at all leads and lags. $\mathbf{D}_{0}$ and $\mathbf{D}_{1}$ correspond to the price responses to innovations $\boldsymbol{\eta}_{t}$ at time $t$ (contemporaneous) and $t+1$ (one period later). $C S_{i}$ and $I S_{i}$ are the CS and IS for market $i$ respectively. The first row of the table is based on $b_{0,1}^{P}=b_{0,2}^{P}=0$, $b_{0,1}^{T}=0$ and $b_{0,2}^{T}=\varepsilon \neq 0$. The second row is based on $b_{0,1}^{P}=\varepsilon-1, b_{0,2}^{P}=0$, and $b_{0,1}^{T}=-b_{0,2}^{T}=\delta \neq 0$. The IS values are based on the zero covariance restriction on the reduced form errors.

\begin{tabular}{cccccc}
\hline $\mathbf{D}_{0}$ & $\mathbf{D}_{1}$ & $\mathrm{CS}_{1}$ & $\mathrm{CS}_{2}$ & $\mathrm{IS}_{1}$ & $\mathrm{IS}_{2}$ \\
\hline$\left(\begin{array}{cc}1 & 0 \\
1 & \varepsilon\end{array}\right)$ & $\left(\begin{array}{cc}0 & 0 \\
0 & -\varepsilon\end{array}\right)$ & 1 & 0 & 1 & 0 \\
$\left(\begin{array}{cc}\varepsilon & \delta \\
1 & -\delta\end{array}\right)$ & $\left(\begin{array}{cc}1-\varepsilon & -\delta \\
0 & \delta\end{array}\right)$ & 0.5 & 0.5 & $\frac{\varepsilon}{1+\varepsilon}$ & $\frac{1}{1+\varepsilon}$ \\
\hline
\end{tabular}

\section{Table 2: IS from Stylized Structural Models}

This table reports the analytical results of the information share (IS) based on the three stylized microstructure models presented in subsection 3.1 under the zero covariance restriction (27).

\begin{tabular}{llll}
\hline Model & \multicolumn{1}{c}{$\mathrm{IS}_{1}$} & \multicolumn{1}{c}{$\mathrm{IS}_{2}$} & \multicolumn{1}{c}{$\Delta$} \\
\hline 1 & $\Delta^{-1}\left(1+b_{0,1}^{P}\right) b_{0,2}^{T}$ & $-\Delta^{-1}\left(1+b_{0,2}^{P}\right) b_{0,1}^{T}$ & $\left(1+b_{0,1}^{P}\right) b_{0,2}^{T}-\left(1+b_{0,2}^{P}\right) b_{0,1}^{T}$ \\
2 & $\Delta^{-1}\left(1+b_{0,1}^{P}\right) b_{0,2}^{T}$ & $-\Delta^{-1} b_{0,2}^{P} b_{0,1}^{T}$ & $\left(1+b_{0,1}^{P}\right) b_{0,2}^{T}-b_{0,2}^{P} b_{0,1}^{T}$ \\
3 & $\Delta^{-1} \delta_{1} b_{0,2}^{T}$ & $-\Delta^{-1} \delta_{2} b_{0,1}^{T}$ & $\delta_{1} b_{0,2}^{T}-\delta_{2} b_{0,1}^{T}$ \\
\hline
\end{tabular}




\section{Table 3: CS and IS Estimates from Simulated Prices}

This table reports the estimates of the information share (IS) and component share (CS) from the price data simulated from the following partial adjustment model:

$$
\begin{aligned}
p_{i, t} & =p_{i, t-1}+\delta_{i}\left(m_{t}-p_{i, t-1}\right)+b_{0, i}^{T} \eta_{t}^{T} \\
m_{t} & =m_{t-1}+\eta_{t}^{P}
\end{aligned}
$$

where the structural errors $\boldsymbol{\eta}_{t}=\left(\eta_{t}^{P}, \eta_{t}^{T}\right)^{\prime}$ are normally distributed with zero means, and diagonal covariance matrix $\operatorname{diag}\left(\sigma_{P}^{2}, \sigma_{T}^{2}\right)$, and are mutually uncorrelated at all leads and lags. The simulation parameterization is $\delta_{1}=0.8, \delta_{2}=0.2, b_{0,1}^{T}=0.5, b_{0,2}^{T}=-0.5, \sigma_{P}^{2}=1$ and $\sigma_{T}^{2}=0.64$. For each sample, the VEC model (2) is fitted with the BIC optimal lag length and the CS and IS values are computed using (11) and (7). The numbers in each column represent averages over the simulations with Monte Carlo standard deviations in

\begin{tabular}{|c|c|c|c|c|c|c|c|c|}
\hline & \multirow[b]{2}{*}{$\begin{array}{c}\text { True } \\
\text { Value }\end{array}$} & \multicolumn{7}{|c|}{ Sample Size } \\
\hline & & 100 & 250 & 500 & 750 & 1000 & 5000 & 10000 \\
\hline$\alpha_{1}$ & & $\begin{array}{c}-0.196 \\
(0.077)\end{array}$ & $\begin{array}{c}-0.177 \\
(0.045)\end{array}$ & $\begin{array}{c}-0.167 \\
(0.031)\end{array}$ & $\begin{array}{c}-0.165 \\
(0.025)\end{array}$ & $\begin{array}{l}-0.163 \\
(0.022)\end{array}$ & $\begin{array}{c}-0.161 \\
(0.010)\end{array}$ & $\begin{array}{c}-0.161 \\
(0.007)\end{array}$ \\
\hline$\alpha_{2}$ & & $\begin{array}{c}0.161 \\
(0.038)\end{array}$ & $\begin{array}{c}0.160 \\
(0.022)\end{array}$ & $\begin{array}{c}0.159 \\
(0.015)\end{array}$ & $\begin{array}{c}0.161 \\
(0.012)\end{array}$ & $\begin{array}{c}0.160 \\
(0.011)\end{array}$ & $\begin{array}{c}0.160 \\
(0.005)\end{array}$ & $\begin{array}{c}0.160 \\
(0.003)\end{array}$ \\
\hline$K-1$ & & $\begin{array}{c}1.001 \\
(0.032)\end{array}$ & $\begin{array}{c}1 \\
(0.000)\end{array}$ & $\begin{array}{c}1 \\
(0.000)\end{array}$ & $\begin{array}{c}1 \\
(0.000)\end{array}$ & $\begin{array}{c}1 \\
(0.000)\end{array}$ & $\begin{array}{c}1 \\
(0.000)\end{array}$ & $\begin{array}{c}1 \\
(0.000)\end{array}$ \\
\hline$\psi_{1}$ & 1 & $\begin{array}{c}0.929 \\
(0.328)\end{array}$ & $\begin{array}{c}0.959 \\
(0.204)\end{array}$ & $\begin{array}{c}0.982 \\
(0.153)\end{array}$ & $\begin{array}{c}0.992 \\
(0.123)\end{array}$ & $\begin{array}{c}0.990 \\
(0.106)\end{array}$ & $\begin{array}{c}0.996 \\
(0.050)\end{array}$ & $\begin{array}{c}0.998 \\
(0.035)\end{array}$ \\
\hline$\psi_{2}$ & 1 & $\begin{array}{c}1.050 \\
(0.302)\end{array}$ & $\begin{array}{c}1.028 \\
(0.185)\end{array}$ & $\begin{array}{c}1.016 \\
(0.131)\end{array}$ & $\begin{array}{c}1.005 \\
(0.108)\end{array}$ & $\begin{array}{c}1.003 \\
(0.091)\end{array}$ & $\begin{array}{c}1.003 \\
(0.041)\end{array}$ & $\begin{array}{c}1.002 \\
(0.029)\end{array}$ \\
\hline$\rho$ & 0 & $\begin{array}{l}-0.002 \\
(0.105)\end{array}$ & $\begin{array}{c}0.002 \\
(0.063)\end{array}$ & $\begin{array}{c}0.002 \\
(0.047)\end{array}$ & $\begin{array}{c}0.000 \\
(0.037)\end{array}$ & $\begin{array}{l}-0.000 \\
(0.032)\end{array}$ & $\begin{array}{c}0.000 \\
(0.014)\end{array}$ & $\begin{array}{c}0.000 \\
(0.010)\end{array}$ \\
\hline $\mathrm{IS}_{L, 1}$ & 0.800 & $\begin{array}{c}0.672 \\
(0.178)\end{array}$ & $\begin{array}{c}0.736 \\
(0.107)\end{array}$ & $\begin{array}{c}0.762 \\
(0.076)\end{array}$ & $\begin{array}{c}0.777 \\
(0.061)\end{array}$ & $\begin{array}{c}0.779 \\
(0.051)\end{array}$ & $\begin{array}{c}0.792 \\
(0.024)\end{array}$ & $\begin{array}{c}0.795 \\
(0.016)\end{array}$ \\
\hline $\mathrm{IS}_{U, 1}$ & 0.800 & $\begin{array}{c}0.742 \\
(0.167)\end{array}$ & $\begin{array}{c}0.777 \\
(0.102)\end{array}$ & $\begin{array}{c}0.793 \\
(0.072)\end{array}$ & $\begin{array}{c}0.800 \\
(0.060)\end{array}$ & $\begin{array}{c}0.800 \\
(0.050)\end{array}$ & $\begin{array}{c}0.801 \\
(0.023)\end{array}$ & $\begin{array}{c}0.801 \\
(0.016)\end{array}$ \\
\hline $\mathrm{CS}_{1}$ & 0.500 & $\begin{array}{c}0.465 \\
(0.116)\end{array}$ & $\begin{array}{c}0.481 \\
(0.072)\end{array}$ & $\begin{array}{c}0.491 \\
(0.053)\end{array}$ & $\begin{array}{c}0.497 \\
(0.043)\end{array}$ & $\begin{array}{c}0.496 \\
(0.037)\end{array}$ & $\begin{array}{c}0.498 \\
(0.018)\end{array}$ & $\begin{array}{c}0.499 \\
(0.012)\end{array}$ \\
\hline
\end{tabular}
parentheses. Total simulations $=1000$. 


\section{Table 4: CS and IS Estimates from Simulated Prices}

This table reports the estimates of the information share (IS) and component share (CS) from the price data simulated from the following partial adjustment model:

$$
\begin{aligned}
p_{i, t} & =p_{i, t-1}+\delta_{i}\left(m_{t}-p_{i, t-1}\right)+b_{0, i}^{T} \eta_{t}^{T} \\
m_{t} & =m_{t-1}+\eta_{t}^{P}
\end{aligned}
$$

where the structural errors $\boldsymbol{\eta}_{t}=\left(\eta_{t}^{P}, \eta_{t}^{T}\right)^{\prime}$ are normally distributed with zero means, and diagonal covariance matrix $\operatorname{diag}\left(\sigma_{P}^{2}, \sigma_{T}^{2}\right)$, and are mutually uncorrelated at all leads and lags. The simulation parameterization is $\delta_{1}=0.8, \delta_{2}=0.2, b_{0,1}^{T}=0.9, b_{0,2}^{T}=-0.1, \sigma_{P}^{2}=1$ and $\sigma_{T}^{2}=1.778$. For each sample, the VEC model (2) is fitted with the BIC optimal lag length and the CS and IS values are computed using (11) and (7). The numbers in each column represent averages of the estimates over the simulations with Monte Carlo standard deviations in parentheses. Total simulations $=1000$.

\begin{tabular}{ccccccccc}
\hline & & \multicolumn{7}{c}{ Sample Size } \\
& $\begin{array}{c}\text { True } \\
\text { Value }\end{array}$ & 100 & 250 & 500 & 750 & 1000 & 5000 & 10000 \\
\hline$\alpha_{1}$ & & -0.583 & -0.568 & -0.558 & -0.557 & -0.555 & -0.555 & -0.554 \\
& & $(0.112)$ & $(0.069)$ & $(0.047)$ & $(0.039)$ & $(0.033)$ & $(0.015)$ & $(0.010)$ \\
$\alpha_{2}$ & & 0.058 & 0.059 & 0.060 & 0.061 & 0.060 & 0.061 & 0.061 \\
& & $(0.019)$ & $(0.011)$ & $(0.008)$ & $(0.006)$ & $(0.006)$ & $(0.003)$ & $(0.002)$ \\
$K-1$ & & 1.003 & 1 & 1 & 1 & 1 & 1 & 1 \\
& & $(0.054)$ & $(0.000)$ & $(0.000)$ & $(0.000)$ & $(0.000)$ & $(0.000)$ & $(0.000)$ \\
$\psi_{1}$ & 0.385 & 0.353 & 0.365 & 0.377 & 0.381 & 0.380 & 0.383 & 0.383 \\
& & $(0.162)$ & $(0.099)$ & $(0.075)$ & $(0.060)$ & $(0.051)$ & $(0.024)$ & $(0.017)$ \\
$\psi_{2}$ & 3.462 & 3.466 & 3.451 & 3.462 & 3.462 & 3.448 & 3.458 & 3.460 \\
& & $(0.985)$ & $(0.605)$ & $(0.433)$ & $(0.351)$ & $(0.293)$ & $(0.132)$ & $(0.096)$ \\
$\rho$ & 0 & -0.015 & -0.006 & -0.003 & -0.004 & -0.004 & -0.001 & -0.000 \\
& & $(0.101)$ & $(0.063)$ & $(0.044)$ & $(0.037)$ & $(0.032)$ & $(0.014)$ & $(0.010)$ \\
$\mathrm{IS}_{L, 1}$ & 0.308 & 0.238 & 0.263 & 0.281 & 0.289 & 0.291 & 0.300 & 0.303 \\
& & $(0.141)$ & $(0.091)$ & $(0.068)$ & $(0.057)$ & $(0.048)$ & $(0.023)$ & $(0.015)$ \\
$\mathrm{IS}_{U, 1}$ & 0.308 & 0.304 & 0.308 & 0.313 & 0.316 & 0.315 & 0.311 & 0.310 \\
& & $(0.153)$ & $(0.095)$ & $(0.069)$ & $(0.057)$ & $(0.049)$ & $(0.022)$ & $(0.015)$ \\
$\mathrm{CS}_{1}$ & 0.1 & 0.092 & 0.096 & 0.098 & 0.099 & 0.099 & 0.010 & 0.010 \\
& & $(0.032)$ & $(0.019)$ & $(0.014)$ & $(0.011)$ & $(0.010)$ & $(0.005)$ & $(0.003)$ \\
\hline
\end{tabular}




\section{Table 5: CS and IS Estimates from Simulated Prices Sampled at Different Frequencies}

This table reports the estimates of the information share (IS) and component share (CS) from the price data simulated from the following partial adjustment model:

$$
\begin{aligned}
p_{i, t} & =p_{i, t-1}+\delta_{i}\left(m_{t}-p_{i, t-1}\right)+b_{0, i}^{T} \eta_{t}^{T} \\
m_{t} & =m_{t-1}+\eta_{t}^{P}
\end{aligned}
$$

where the structural errors $\boldsymbol{\eta}_{t}=\left(\eta_{t}^{P}, \eta_{t}^{T}\right)^{\prime}$ are normally distributed with zero means, and diagonal covariance matrix $\operatorname{diag}\left(\sigma_{P}^{2}, \sigma_{T}^{2}\right)$, and are mutually uncorrelated at all leads and lags. The simulation parameterization is $\delta_{1}=0.8, \delta_{2}=0.2, b_{0,1}^{T}=0.9, b_{0,2}^{T}=-0.1, \sigma_{P}^{2}=1$ and $\sigma_{T}^{2}=1.778$. For each sample, the VEC model is fitted to data sampled at increments $m=1,2, . ., 5$ with the BIC optimal lag length and the CS and IS values are computed using (11) and (7). Then numbers in each column represent averages of the estimates over the

\begin{tabular}{|c|c|c|c|c|c|c|}
\hline & \multirow[b]{2}{*}{$\begin{array}{c}\text { True } \\
\text { Value }\end{array}$} & \multicolumn{5}{|c|}{ Sampling Increment, $m$} \\
\hline & & 1 & 2 & 3 & 4 & 5 \\
\hline$\alpha_{1}$ & & $\begin{array}{c}-0.558 \\
(0.047)\end{array}$ & $\begin{array}{c}-0.719 \\
(0.093)\end{array}$ & $\begin{array}{l}-0.761 \\
(0.139)\end{array}$ & $\begin{array}{l}-0.777 \\
(0.188)\end{array}$ & $\begin{array}{c}-0.753 \\
(0.232)\end{array}$ \\
\hline$\alpha_{2}$ & & $\begin{array}{c}0.060 \\
(0.008)\end{array}$ & $\begin{array}{c}0.091 \\
(0.025)\end{array}$ & $\begin{array}{c}0.116 \\
(0.048)\end{array}$ & $\begin{array}{c}0.143 \\
(0.076)\end{array}$ & $\begin{array}{c}0.177 \\
(0.113)\end{array}$ \\
\hline$K-1$ & & $\begin{array}{c}1 \\
(0.000)\end{array}$ & $\begin{array}{c}1 \\
(0.000)\end{array}$ & $\begin{array}{c}1.003 \\
(0.055)\end{array}$ & $\begin{array}{c}1.002 \\
(0.045)\end{array}$ & $\begin{array}{c}1.001 \\
(0.032)\end{array}$ \\
\hline$\psi_{1}$ & 0.385 & $\begin{array}{c}0.377 \\
(0.075)\end{array}$ & $\begin{array}{c}0.315 \\
(0.102)\end{array}$ & $\begin{array}{c}0.296 \\
(0.135)\end{array}$ & $\begin{array}{c}0.299 \\
(0.171)\end{array}$ & $\begin{array}{c}0.323 \\
(0.214)\end{array}$ \\
\hline$\psi_{2}$ & 3.462 & $\begin{array}{c}3.462 \\
(0.433)\end{array}$ & $\begin{array}{c}2.453 \\
(0.358)\end{array}$ & $\begin{array}{c}1.927 \\
(0.378)\end{array}$ & $\begin{array}{l}1.600 \\
(0.387)\end{array}$ & $\begin{array}{c}1.363 \\
(0.431)\end{array}$ \\
\hline$\rho$ & 0 & $\begin{array}{l}-0.003 \\
(0.044)\end{array}$ & $\begin{array}{c}0.441 \\
(0.051)\end{array}$ & $\begin{array}{c}0.625 \\
(0.048)\end{array}$ & $\begin{array}{c}0.717 \\
(0.045)\end{array}$ & $\begin{array}{c}0.765 \\
(0.043)\end{array}$ \\
\hline $\mathrm{IS}_{L, 1}$ & 0.308 & $\begin{array}{c}0.281 \\
(0.068)\end{array}$ & $\begin{array}{c}0.120 \\
(0.060)\end{array}$ & $\begin{array}{c}0.078 \\
(0.060)\end{array}$ & $\begin{array}{c}0.065 \\
(0.060)\end{array}$ & $\begin{array}{c}0.068 \\
(0.065)\end{array}$ \\
\hline $\mathrm{IS}_{U, 1}$ & 0.308 & $\begin{array}{c}0.313 \\
(0.069)\end{array}$ & $\begin{array}{c}0.515 \\
(0.098)\end{array}$ & $\begin{array}{c}0.648 \\
(0.109)\end{array}$ & $\begin{array}{c}0.723 \\
(0.114)\end{array}$ & $\begin{array}{c}0.780 \\
(0.121)\end{array}$ \\
\hline $\mathrm{CS}_{1}$ & 0.100 & $\begin{array}{c}0.098 \\
(0.014)\end{array}$ & $\begin{array}{c}0.114 \\
(0.036)\end{array}$ & $\begin{array}{c}0.137 \\
(0.065)\end{array}$ & $\begin{array}{c}0.166 \\
(0.100)\end{array}$ & $\begin{array}{c}0.211 \\
(0.144)\end{array}$ \\
\hline
\end{tabular}
simulations with Monte Carlo standard deviations in parentheses. Total simulations $=1000$. 